\section{Cardiopulmonary resuscitation ethics: a response to Michael Ardagh}

SIR

There are some important flaws in Michael Ardagh's reasoning. ${ }^{1}$

1. Cardiopulmonary resuscitation (CPR) is a "blanket term" for different interventions. Curative and supportive treatments have different ethical contexts and cannot be discussed at the same level. It is imperative to ascribe curative interventions within CPR (defibrillation, pneumothorax drainage, etc) the same status as any other curative intervention, such as antibiotics for infections or surgery for appendicitis. Then we will be able to discuss the ethical context of purely supportive measures such as chest compressions. To address the "ethics of CPR" is a dangerous misnomer.

The preferences of emergency personnel ${ }^{2}$ suggest the willingness to undergo curative interventions early during CPR, but not protracted supportive interventions. Conversely, withholding curative interventions during CPR should only be considered when any curative treatments would also be withheld.

2. Cardiopulmonary resuscitation is performed to offer the patient a benefit. However, CPR as a whole is only marginally effective. ${ }^{3}$ Separating patients who had a curative intervention from those who had only supportive procedures, the difference in the outcomes of different CPR settings becomes evident (for example, survival: ventricular fibrillation $19 \%$, Asystole $2 \%{ }^{4}$ ), and efficacy is important for the ethical content of the act of resuscitation.

Supportive measures are needed if there is to be maintained resuscitability while the patient is assessed for curable illness. It is necessary to define those CPR interventions which have been proved to be curative, and to assess the patient focusing on the indication or otherwise to perform such interventions. Everything else must be ascribed research status. Only then can we discuss what the supportive interventions are intended to do.

3. Central to Ardagh's article is the capacity for surrogates to make decisions. A surrogate is an individual caught between his or her personal drives (socially acceptable decision regarding other relatives and acquaintances, professionally acceptable decision, etc) and the identity the surrogate assigns to the patient (for example, a loved one, an instance of cardiac arrest). The result is a subordination of the patient's autonomy to the drives of the surrogate chosen. Professional detachment equates to addressing a stereotyped patient instead of the real one.

The surveys of emergency personnel $^{2}$ show that we do not wish for ourselves what we daily do to our patients. This is the basic flaw: I may well wish to preserve my loved ones when I would not wish to be preserved myself.

4. Principled ethics are a particular approach to ethics. Beauchamp and Childress $^{5}$ also refer to other approaches, and relation-based ethics is particularly relevant for a profession defined around the doctor-patient relationship. Relationships are a source of bilateral duties and expectations which carry an ethical content from the moment they are established. Regarding the medical relationship, the "duty of care" is immediately established, as is the expectation that the patient will accept such care. The flaw is to forget that the cardiac arrest patient did not necessarily accept the establishment of the relationship, and the duty of care is imposed on the patient.
In medical relationships where clearly the patient has no powerpsychiatric incompetence, child protection, etc-are concerned, the framework of the medical intervention is socially defined, and has little to do with ethics as the expression of autonomy, but rather has to do with a social discourse about ideological coherence-the principles of ethics in their "power discourse" mode, enabling the medical profession to make unilateral decisions in the patient's name. Within this framework there is no space for autonomy, the individual is not called to define himself: society assigns an identity to individuals and regulates the mode of action to be observed.

5. Interestingly, Beauchamp and Childress concluded "that we should abandon substituted judgment insofar as possible in law and in ethics..." .6

6. Western culture lives within the opposition between life and death. Malpas $^{7}$ argued for the necessity of death to create the "unity of a life", the life project which ultimately enables autonomy. Consequently, our attitude towards death has implications for the expression of our autonomy. It is important to define the characteristics that allow the denial of death, which justifies intervention as a default, in contradiction of the medical ethical framework (which demands patients' consent). This contradiction is so profound that we must search for the reason why, before affirming a common ethical framework.

In summary, so-called CPR ethics is a dangerous misnomer for a particular discussion of the ethics of lifesupporting treatment, in a context where decisions have to be made very rapidly. To situate the discussion properly, defining its scope and expressing the limitations of the action and conceptual models used, will be helpful. 


\section{References}

1 Ardagh M. Resurrecting autonomy during resuscitation-the concept of professional substituted judgment. 8.

2 Hauswald M, Tanberg D. Out-ofhospital resuscitation preferences of emergency health care workers. Ameriemergency health care workers. American fournal of

3 Hiberman M, Kutner J, Parsons D, 3 Hiberman M, Kutner J, Parsons D, cal care: ethical analysis of issues in cardiopulmonary resuscitation (CPR) fournal of Medical Ethics 1997;23,6: 361-7.

4 Perers E, Abrahamsson P, Bång A, Engdahl J, Lindqvist J, Karlson BW, et al. There is a difference in characteristics and outcome between women and men who suffer out of hospital cardiac arrest. Resuscitation 1999;40:133-40.

5 Beauchamp TL, Childress JF. Principles of biomedical ethics [4th ed]. New York: Oxford University Press, 1994.

6 See reference 5: 173

See reference Malpas J. Death and the unity of a life. n: Malpas J, Solomon C, eds. Death and philosophy. London/New York: Routledge, 1998.

J CALINAS-CORREIA, MD(LICMED) DIMC RCSED, 16 Roskear, Camborne, Cornwall,

TR14 8DN

\section{Informed consent}

SIR

I was concerned to read the following statement by Anne Zachary (Doctor) published by Marilyn Lawrence, Editor, (Tavistock practitioner) and Coeditors, in Psychoanalytic Psychotherapy, The fournal of the Association of For Psychoanalytic Psychotherapists in the NHS. "Whilst we do not want to raise too starkly ourselves the moral, ethical, legal problem of sharing what the unsophisticated patient believes to be confidential with a third party, thereby destroying our own model which we believe in for the greater good... ." This was supported by another statement in a published article in the next edition by Maureen Marks of the Institute of Psychiatry: "... it may be that we have to decide that sometimes our concern for patient's privacy is worth sacrificing to further the psychoanalytical cause". ${ }^{2}$ This reveals a seeming glaring ignorance not only of ethical principles of, for example, honesty and trust but also of formal guidelines and procedures in the National Health Service (NHS). It is pertinent that they do practise in the NHS, because service users have established rights to FULLY INFORMED consent to any treatment and to give or withhold permission for use of their information. Therefore the deliberate intention to deceive certain groups of persons, as wrapped up in Anne Zachary's convoluted statement, reveals a rather worrying attitude to the rights of clients which are indeed now more properly protected by General Medical Council (GMC) guidelines, Data Protection Law, common law rights to privacy and, importantly, Department of Health guidelines which support the rights of clients to consent.

To find these being breached at a time when the public has lost a great deal of trust in NHS practitioners, in a discipline underpinned by principles of trust and a confidential relationship, is deserving of some rigorous self analysis by some psychoanalysts, including a consideration of the history of medicine, which is strewn with the corpses of those who have been subjected to the abuse of their rights by small groups of clinicians who have claimed to be acting "for the common good", usually in secretive and closed organisations of which the public in general had little knowledge.

\section{References}

1 Zachary A. Supervision and its vicissitudes [book review]. Psychoanalytic Psychotherapy. The fournal of the Association for Psychoanalytic Psychotherapist in the NHS 1999;13,2:196.

2 Marks M. Talking cure. BBC 2 [review]. Psychoanalytic Psychotherapy. The fournal of the Association for Psychoanalytic Psychotherapists in the NHS 2000, 14,1:76.

SUSANNE STEVENS 66 Pen-Y-Lan Road Roath CF23 $5 \mathrm{HW}$

\section{Informed consent: response}

SIR

I would like to acknowledge with regret that my sentence, of which $\mathrm{Ms}$ Stevens quotes half, is convoluted. A book review ${ }^{1}$ is necessarily condensed and perhaps if it creates a problem it is best to read the book. But, in the complex legal, moral and ethical dilemmas arising in subjects such as confidentiality, it is highly dangerous to take half a sentence out of context (and I note that Ms Stevens does this to Maureen Marks's review ${ }^{2}$ also) and use it to discuss a separate agenda, ie secrecy within the National Health Service (NHS)

I would draw Ms Stevens's attention to another book review ${ }^{3}$ of mine, or more wisely, to the book itself. Counselling, Psychotherapy and the Law, by Peter Jenkins, published in 1997 by Sage, in London, usefully separates out two opposite situations. There are those situations in which the therapist is custodian of confidential information and has to decide whether in certain circumstances, which are precisely defined, there are grounds for disclosure. Then there are those situations, where external agencies are demanding disclosure. This might be a legal demand but can be extended to include a patient's wish to see his or her own records, legally the property of the relevant trust in the NHS. "It is surprising how entangled these separate issues can become, in a discussion where one party may be worrying about the former and the other about the latter." I fear that something of this nature is what is happening between Ms Stevens and myself. We must be very clear about which discussion we are having, using which professional guidelines and structures. Otherwise there is just muddle and misunderstanding.

Paradoxically, one aspect of secrecy in the NHS is highlighted in my review of the "supervision book" as a cause of risk. ${ }^{4}$ As the NHS professional I am arguing for proper consultation between members of the team. This extends to a supervisor of course. In the private setting this is adapted properly so that the supervisor does not know who the patient is. There are firm, established professional guidelines both for the NHS and private practice. Ms Stevens is arguing for the rights of patients. Again, there are firm and established guidelines. But these are different guidelines and the reality in a dispute is necessarily a compromise reached through negotiation.

There is currently much media attention to the impossible decisions which have to be made around the conjoined twins and the paradoxically conflicting moral and ethical opinions involved. "The extraordinary thing about these life and death medical ethics is that they knit a tangled web of contradictory principles." Toynbee highlights that having objected so strongly to the planned death of a vegetative patient, the pro-life group find themselves supporting the death of twins in objecting to surgery to save one of them.

Perhaps we professionals and patients alike should take this opportunity to give each other a little more width before protesting unhelpfully. 


\section{References}

1 Zachary A. Supervision and its vicissitudes [book review]. Psychoanalytic Psychotherapy 1999;13,2:196.

2 Marks M. Talking cure. BBC 2 [reMiew]. Psychoanalytic Psychotherapy
view
3 Zachary A. Counselling, psychotherapy and the law [book review]. Psy89.

4 Martindale B, Morner M, Rodriguez MEC, Vidit J-P, eds. Supervision and its vicissitudes. London: Karnac Books, 1997.
5 Toynbee P. Two into one. The Guardian 2000 Sept 8: 23.

ANNE ZACHARY clo FME Editorial 38 Pagoda Avenue Richmond, Surrey 